\title{
Three-Dimensional Assessment of the Knowledge Production System: Region-City-Organization
}

\author{
Andrey S. Mikhaylov ${ }^{1,2}$, Anna A. Mikhaylova ${ }^{1}$ and Dmitry V. Hvaley ${ }^{1}$ \\ ${ }^{1}$ Immanuel Kant Baltic Federal University, Kaliningrad, Russia \\ ${ }^{2}$ Institute of Geography of the Russian Academy of Sciences, Moscow, Russia \\ mikhailov.andrey@yahoo.com \\ tikhonova.1989@mail.ru \\ hvaley gusev@mail.ru
}

\begin{abstract}
Conceptualization of the region as an integral territorial system of knowledge production has formed a widely used research strategy for innovation studies within regional boundaries. Regional level studies are supported by detailed innovation statistics, which is unavailable for smaller administrative-territorial units, such as municipalities or settlements. The development of spatial scientometrics gave impetus for a new round of research on knowledge and innovation geography with a closer approximation in the context of cities and urban agglomerations. The scope of recent research also includes individual organizations that generate new knowledge or innovation. Despite the topic prominence, the entire array of studies is fragmented, and connections between different levels are not established: region - city - organization. Whereas this is critically important for the implementation of an effective innovation policy. In this regard, in this study, we test the hypothesis that the aggregate data obscures a wide variety of knowledge nodes, which are represented by a dominant knowledge centre. In the case of the region, such centres are often the largest cities, and in the case of cities - the largest organizations. The research design is focused on assessing the knowledge production at a multiscale level - organization, city and region, using the method of spatial scientometrics. The example of the Russian Federation illustrates well the territorial and institutional diversity in the distribution of knowledge production centres of different levels due to its great length and complexity of the structure of the national innovation system. This fact determines the high degree of heterogeneity of the Russian innovation space at the interregional, intercity and inter-organizational levels. The research results show a strong correlation between the knowledge profiles of regions and their primary knowledge-generating cities (KGCs). In cases of a strong central-peripheral structure of the regional knowledge production system, the regional profile completely coincides with the profile of its primary KGC. The knowledge capacity of second-tier cities remains hidden. At the city level, the identified trend is exacerbated. The absence of a pronounced leader among knowledge-intensive organizations (KIOs) against organizational diversity leads to a strong blur of the effectiveness of the knowledge production capabilities of a city. The example of Khabarovsk shows that the research profile of a city in a given situation may not repeat the most productive KIO, but, on the contrary, a weak one. Thus, the three-dimensional region-city-organization approach captures local specifics and organizational diversity, encompassing the entire set of elements of a regional knowledge production system. The study concludes with recommendations for a knowledge management policy at a tiered level.
\end{abstract}

Keywords: innovation geography, geography of knowledge, spatial scientometrics, knowledge production system, excellence centre, research centre, knowledge-intensive organization

\section{Introduction}

Knowledge has come to the centre of attention across disciplines and concepts for being the most valuable asset of growth and competitiveness. The ability to manage knowledge is increasingly recognized to be critical in today's shift towards a knowledge-based and innovation economy. National and regional policies foster the knowledge production function of the territorial innovation systems with numerous public and private initiatives driving innovative activity and supporting knowledge-intensive organizations - KIOs (Perret, 2019; Sawant and Jain, 2017; Stejskal and Hajek, 2016). Most of these initiatives are taking place on a regional level, which is generally conceived as an optimal scale for capturing the aggregate and a holistic overview of the knowledgegenerating ecosystem (Bathelty and Cohendet, 2014; Scaringella and Radziwon, 2018; Tödtling and Trippl, 2018).

Overall, regional level studies dominate the research design on knowledge-based and innovation-driven economies, providing input for state policies. With that, researchers increasingly raise concerns on significant limitations related to this generalized outlook on innovation systems. As knowledge is unevenly distributed both at inter- and intra-regional space, regional innovation systems can be highly divergent and asymmetrical in its spatial context (Asheim et al., 2019; Davids and Frenken, 2018; Isaksen and Trippl, 2017). Strong polarization is often observed towards large cities. Cities and urban agglomerations increasingly become a focus in knowledge and innovation studies as the nodes where a major part of regional intellectual capital being generated and 
accumulated (Carrillo et al, 2014; Sánchez-Moral et al., 2018; Yigitcanlar, 2009; Yigitcanlar and Lonnqvist, 2013). However, the fact of spatial clustering alone is not enough as dedicated policies should be in place for creating a favourable innovative climate and an innovative milieu with a clear understanding of stakeholders - innovative firms, research-intensive organizations, science and technology institutions, academia, knowledge-intensive public organizations, etc. (Uyarra et al., 2017; Yigitcanlar, 2014).

When describing an innovation potential of a region or a city, researchers and practitioners often refer to particular organizations - Google, Apple, Xerox, Cisco, Amazon in Silicon Valley (Berger and Brem, 2016), Astra Zeneca, Lundbeck, LEO Pharma, and Novo Nordisk in Oresund cross-border region (Czarny, 2017; Park, 2016), Ericsson, IBM Svenska, Telia-Sonera in Stockholm agglomeration high-tech sector (Solesvik, 2017). This is due to the significant role of an institution played in the geography of innovation (Shearmur, 2017). Some knowledge production and innovation systems are more diverse and poly-centric than others; some have established a coherent structure with aligned aspirations and strategic priorities, while others lack solidarity and consistency in numerous public-private initiatives. It is therefore important to develop multi-hierarchical knowledge management to account for the knowledge production system at regional, urban, and organizational levels combined (Carayannis et al., 2018; Clarke et al., 2016; Järvi et al., 2018). Innovation policies require both a broader perspective on the features of the regional innovation system and a narrower perspective in order to focus on the specific innovative needs of knowledge cities as its major elements - the knowledge-generating institutions.

The purpose of this study is to assess the divergence in the knowledge production domain of Russia by conducting a multiscale comparative analysis of research activity. We focus on identifying and comparing the research profile of regions with the profiles of knowledge-generating cities (KGCs) scattered across its territories, as well as with knowledge-intensive organizations (KIOs) concentrated in the urban space. The hypothesis of the study is that regional level study on knowledge production systems is informative only being represented by a single core - a dominant KGC. In the case of a distributed knowledge production system featured by multiple KGCs of a similar scale, the outlook should be held at the city level. Otherwise, when studying aggregated data for regions with distributed knowledge production systems across multiple KGCs, the results are greatly distorted, thus, decreasing data validity for managerial purposes. We also believe that this hypothesis will be valid at a lower hierarchical level - in relation to the city (KGC) and its knowledge-intensive organizations (KIOs). It is expected that understanding the limits of data generalisation will improve the efficiency of knowledge management and resolve the issue of information distortion for decision-making.

\section{Literature review}

\subsection{Spatial scope in studying the knowledge production system}

Knowledge production is found to be place-dependent, rooted in context, and differentiated among locations (Heimeriks and Boschma, 2014). Regional studies dominate the research landscape on knowledge production and innovation systems. Regional clusters, innovative milieux, new industrial spaces, innovation districts, learning regions, regional innovation systems, and other territorial innovation models analysed in a regional context outline the established territorial capital (Camagni, 2017; Fernandes et al., 2020; Prokop and Stejskal, 2018), reveal the existing inter-organizational networks within the 'triple-quadruple-quintuple helix' framework (Carayannis et al., 2018; Leydesdorff, 2012; Mikhaylov, 2018), and enable building projections over the regional innovation trajectories (Capello and Lenzi, 2018) for developing place-sensitive development policies. The prevalence of regional-level data is largely supported by the availability of statistics representing the innovative activity (Taques et al., 2021), as well as policy recommendations drawn from the research results are easier adopted on a regional level due to administrative and political structure of most countries. Despite the aforementioned advantages of regional studies, the results can be found too generalized and averaged.

Recent research on the geography of knowledge and innovation conclude that cities are the main locus of knowledge production, thus, cities are the optimal scale in capturing the elements and features of innovative activity (Breschi and Lenzi, 2016; Edvardsson et al., 2016). The concepts of knowledge-based urban development (KBUD) and knowledge city have recently emerged as a central topic of scholarly communication and the primary agenda of policymakers (Makkonen and Weidenfeld, 2016; Penco et al., 2020). Cities are defined as locomotives of economic growth integrating and concentrating research activities, technological capacity, and innovative capabilities (Carrillo, 2015; Esmaeilpoorarabi et al., 2016). Urban environments are found to be the natural locus for the hyper-concentration of talents, ideas, competencies, expertise, know-how, the knowledge-intensive and 
innovative organizations, as well as related public institutions that contribute to the generation and diffusion of knowledge by cross-fertilization and synergies (Mikhaylova and Mikhaylov, 2016; Yigitcanlar and Bulu, 2016). The related variety and the institutional thickness present in major cities are particularly decisive in the continuous process of sourcing, aborting and reengineering knowledge, which is essential for creating innovative goods and services with high added value (Edvardsson et al., 2016; Metaxiotis and Ergazakis, 2008).

Studies on knowledge cities and city-region innovation systems have enabled to identify the diversity of the national innovation system being generally highly divergent and limited to a few globally competitive urban innovation systems (for example, Barcelona, Copenhagen, Dubai, Dublin, Helsinki, Istanbul, Melbourne, Montreal, Moscow, Shanghai, Singapore, Stockholm, etc.; Carrillo et al, 2014; Sánchez-Moral et al., 2018; Yigitcanlar, 2009; Yigitcanlar and Lonnqvist, 2013). Above all, a closer look at the elements of the knowledge production system highlights the significance of individual institutions. It is often the case that a few large knowledge-intensive organizations (KIOs) dominate local economies and determine the established knowledge research landscape (Szulanski, 2002; Kogler and Whittle, 2018).

\subsection{Measuring the spatial patterns of the knowledge production process}

One of the prominent research issues is to find an optimal set of indicators and methods to identify, evaluate, monitor, and manage the codified knowledge base of a territory (city, region, country) and its elements (firms, research institutes, universities, etc.). Looking back at the numerous research articles published we can define dozens of quantitative and qualitative measurements of science, technology and innovation (STI) performance. For example, Dziallas and Blind (2019) present a list of 82 unique indicators being either company-specific or reflecting the contextual dimensions of the innovation process. Overall, the STI indicators have developed over time with the evolution of the market, our understanding of the knowledge production and innovation process, the development of statistics, and the spread of ICT (Freeman and Soete, 2009). The choice of indicators used also strongly depends on the scope of the study and the knowledge production cycle - S\&T ('knowledge input') and innovation ('knowledge output').

Innovation activity that implies the commercialization of knowledge has received a considerable development with knowledge(innovation)-output indicators, such as advanced production technologies, the volume of innovative products, the cost of innovation, the number of companies conducting innovative activities (product or process innovation), the balance of export-import of technologies, etc. These indicators are generally sourced from national and international statistics and indicate the innovation performance and productivity (Mohnen, 2019). Research activity that determines the 'knowledge input' stage is focusing on the capacity of the territorial innovation system to generate knowledge for possible subsequent commercialization or the "knowledge innovation potential' (Liu et al., 2020). A patent-based method (patents for inventions, industrial designs, utility models) is used most often providing legal records of novel and economically valuable ideas (Stek, 2020; Kogler et al., 2018). Kogler et al. (2018) further indicate that patents provide information on the technological details, insights on inventors and knowledge-generating entities, which enable to outline the diversity and scope of the knowledge production system. However, there are limitations related to the propensity of patenting in hightech or knowledge-intensive industries. Scientific publications, on the other hand, provide a rich data on knowledge that is not yet commercially exploited making it an increasingly popular source of S\&T information (Heimeriks et al., 2019).

With the development of electronic abstract and citation databases available online (Scopus, Web of Science, Google Scholar, Dimensions, Lens, Microsoft Academic, PubMed, Semantic Scholar) the use of bibliometrics has become widespread in research on knowledge and innovation. Application of bibliometric analysis with geographical coordinates to the spatial aspects of knowledge production domain is called spatial scientometrics (Frenken and Hardeman, 2009). Due to the nature of the metadata being displayed in the systems and the complexity of attributing geotags, most studies are limited to single hierarchical level (Bornmann \& de Moya Angeon, 2019). One of many methodological complexities with regards to using spatial scientometrics for multidimensional studies is described by Csomos (2018, p. 548): “...some large organisations (universities, multinational corporations, national or international research institutions) house their semi-autonomous but scientifically productive units (university hospitals, corporate research centres) in one city and their command and control centres in another city (corporate headquarters, universities' main campuses, etc.)." Our study enjoys the benefits of using bibliometrics while addressing the limitations of using spatial scientometrics in three-dimensional context - region-city-organization. 


\section{Methodology}

Implementation of the multiscale approach to assessing the knowledge production system required collecting three scientometric datasets - in the context of regions, individual cities, and research-intensive organisations. The method of spatial scientometrics is applied using the Elsevier's Scopus database as the data source (www.scopus.com), covering a publication period of five years - from 2013 to 2017, and citations of 2013-2020. The three-years publication-citation gap ensures the sufficient time for citations to be accumulated. The research scope of this tiered level study on the national knowledge production system covers 83 regions $^{1}$ and 1,118 urban settlements of the Russian Federation listed by the Federal State Statistics Service of the Russian Federation (Rosstat; www.gks.ru). Russia has a strong inter-regional divergence in STI, making it an ideal case for testing the hypothesis set.

The total number of cities affiliated with Scopus-indexed publications over the research period equals to 440, which are defined as Knowledge-Generating Cities - KGCs. The fractional counting approach is not applied in this study, thus, a document affiliated to institutions from multiple cities is fully identified to each city. However, the regional level assessment excludes duplicates. Therefore, there are examples when the sum of articles by cities in a region is greater than the number of papers attributed to this region. This would indicate that researchers from different cities of the same region have co-authored publications. Similar is true for the organisational level of assessment when processing data for knowledge-intensive organizations (KIOs).

The data is collected by generating independent queries for each spatial knowledge production system (organisation, city, region).

The regional-level query string incorporates data on cities and individual institutions. The example of Stavropol region: "AFFILCOUNTRY(Russia*) OR AFFILCITY("Stavropol" OR "Georgiyevsk" OR "Yessentuki" OR "Kislovodsk" OR "Lermontov" OR "Mineralnye Vody" OR "Nevinnomyssk" OR "Pyatigorsk" OR "Svetlograd") OR (AF-ID("North Caucasus Federal University" 60070541) OR AF-ID("Stavropol State Agrarian University" 60084650) OR AFID("Stavropol State Medical University" 60021640) OR AF-ID("Stavropol Research Institute for Plague Control Rospotrebnadzor" 60105240)) AND PUBYEAR > 2012 AND PUBYEAR < 2018".

The city-level query string is limited to publications affiliated with a particular city and/or institutions located this that city. The example of Kaliningrad: "AFFILCOUNTRY (Russia*) AND AFFILCITY ("Kaliningrad") OR (AF-ID ("Immanuel Kant Baltic Federal University" 60031254) OR AF-ID ("Kaliningrad State Technical University" 60018744)) OR AFFIL(ORG("AtlantNIRO") AND PUBYEAR > 2012 AND PUBYEAR < 2018". Search by city enables to allocate organizations that do not have validated profile in Scopus, but feature publications affiliated with the city (as shown in an example of AtlantNIRO). The search results are exported to Excel for defining additional institutions in order to refine the query string. The threshold value for the number of publications indexed by Scopus for organizations is set at 10.

Given the volume of KIOs identified in Scopus, an in-depth evaluation of KIOs performance against KGCs is done using 4 sample cities - Kaliningrad, Perm, Khabarovsk, and Nalchik. These cities are selected for being located in different parts of Russia with a different type of structure of their territorial knowledge-generating systems. Taking into account the established threshold value for publications, the final sample of organizations included in the study is limited to 32 .

Figure 1 shows the distribution of KGCs by region and KIOs by four cities used for in-depth analysis.

\footnotetext{
${ }^{1}$ Note that the collection of data by region implied delimitation of autonomous areas (e.g. the Nenets Autonomous Okrug, the KhantyMansiysk Autonomous Okrug - Yugra, the Yamal-Nenets Autonomous Okrug) from their respective regions - Arkhangelsk and Tyumen regions. Therefore, the knowledge production systems of the three autonomous areas are taken into account independently. The two partially recognized regions of Russia - the Republic of Crimea and the city of federal significance Sevastopol, are excluded from the assessment due to methodological limitations in data collection.
} 

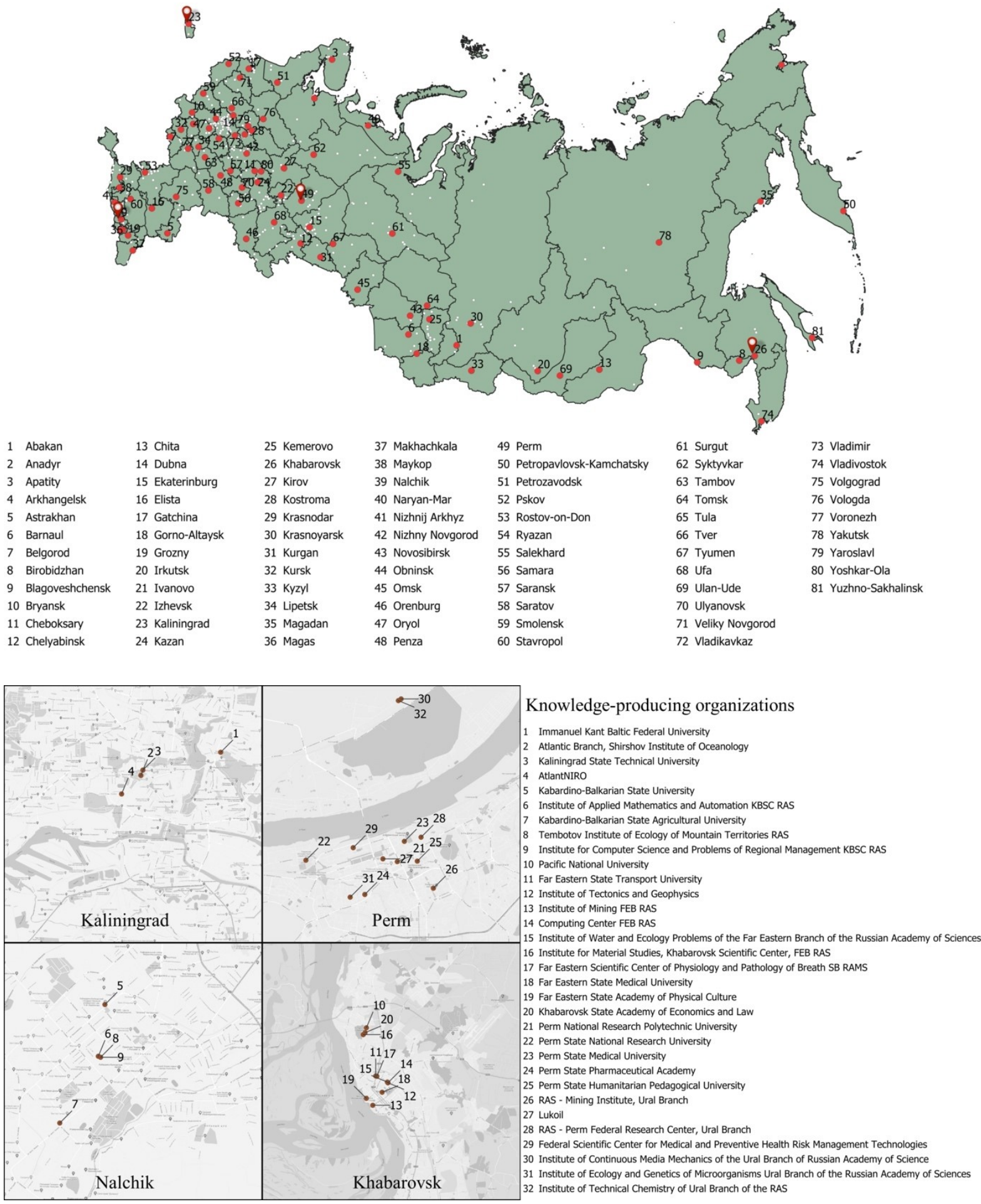

Figure 1: The spatial scope of research on the national knowledge production domain

Data is exported to the SciVal analytical tool (www.scival.com) for conducting bibliometric analysis using the following six indicators: citation per paper; field-weighted citation index (FWCI); share of publications written in international co-authorship (i.e. international collaboration); share of publications written by authors from various institutions of the country (i.e. national collaboration); share of articles published in the Top $10 \%$ Scopus journals by CiteScore (i.e. top journals percentiles); and the volume of scholarly output. The indicators applied ensure comparability between different hierarchical levels - institutions, cities, regions, country, thus, enabling the (de-)fragmentation of the national knowledge domain into multiple levels.

The research design is structured into five stages. 
At the first stage of the study, at the regional level, all KGCs are aligned with their respective regions, while the regions are classified depending on the number of KGCs located on their territory. At the institutional level, all knowledge-intensive organizations (KIOs) are tied to their cities, and cities are classified according to the number of organizations concentrated in them.

The second stage is focused on differentiating primary and secondary KGCs based on the number of publications affiliated with institutions within a region. The number of secondary KGCs within one region ranges from 1 to 54. By a similar method, primary and secondary KIOs were identified for each city. In the four sample regions used for in-depth analysis, there are the following number of secondary organizations: Kaliningrad - 3, Nalchik -4 , Khabarovsk - 10, and Perm - 11.

The third stage of data evaluation shows the contribution share of the primary KGC to the total number of publications in the region. This is calculated as the ratio of the number of publications affiliated with the primary KGC to the aggregate number of publications in the region. The publication shares of primary KGCs in the total number of publications on a regional scale ranged from 30.8 to $100 \%$ depending on the region. Naturally, for regions with a single KGC, the research profile of the KGC fully repeats the research profile of the region. Similar calculations were performed for KIOs within the cities under study. The share of the main KIO in the total number of research output on an urban scale ranged from 24.8 to $74.4 \%$.

At the fourth stage, we have used the F-test function with a two-tailed probability testing the variances in the array of scientometric indicators for regions against KGCs, as well as data for cities against KIOs. The data sets include Field-Weighted Citation Impact, Citations per Publication, International Collaboration, National Collaboration, and Top Journal Percentiles. Overall, the difference in values for this indicator ranges from 0.305 to 1.0 for city-region comparison, and 0.763 to 0.906 for organization-city comparison.

Finally, at the fifth stage, a correlation analysis is conducted of the relationship between the contribution of the primary KGC to the total volume of research output in the region ( $X$ is a factor attribute) and the value characterizing the degree of difference between the scientometric portrait of the region and its primary KGC ( $Y$ is a dependent attribute). The relationship between the contribution of the primary $\mathrm{KIO}$ to the total volume of research output in the KGC ( $x$ is a factor feature) and the value characterizing the degree of difference between the scientometric portrait of the city and its primary organization ( $y$ is a dependent feature).

As part of the correlation analysis, the coefficients of correlation and determination, the average approximation error, and the Fisher's F-test are calculated by the following formulas:

1. correlation coefficient

$R=\sqrt{1-\frac{? ?\left(y_{i}-\mathrm{y} ?_{-i}\right)^{2}}{? ?\left(y_{i}-?\right)^{2}}}$

2. coefficient of determination $R^{2}$ as a squared correlation coefficient;

3. average approximation error

$\overline{\mathrm{A}}=\frac{1}{n} \Sigma\left|\frac{y_{i}-\hat{\mathrm{y}}_{i}}{y_{i}}\right| * 100 \%$

4. Fisher's F-test (actual)

$F=\frac{R^{2}}{1-R^{2}} * \frac{k_{2}}{k_{1}}$

\section{Research results}

The knowledge-generating cities (KGCs) of Russia are highly heterogeneous in their research capabilities and spatial distribution. Figure 2 shows the distribution of the primary KGCs in the regions of Russia, indicating their regional share and the divergence in scientometric indicators. 


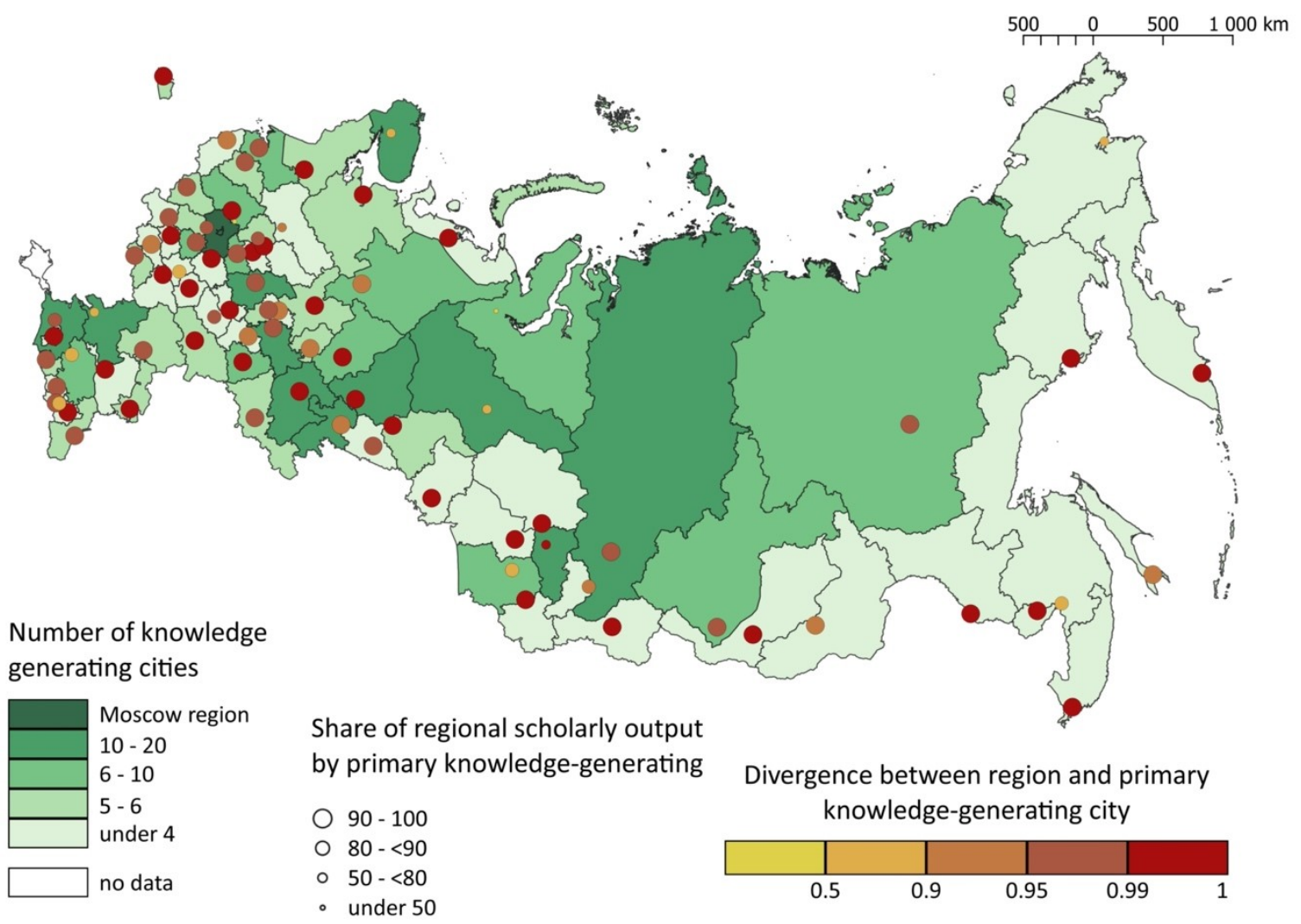

Figure 2: Distribution of primary knowledge generating cities in the regions of Russia, 2013-17

The cubic regression equation is further applied to measure the correlation between the input share to the knowledge production system of primary KGCs to regional total research output and the difference in scientometric portraits of regions and their primary KGCs (Fig. 3). The following equation is used:

$y ?_{-}=-0.002 x^{2}+0.1493 x-2.7347$

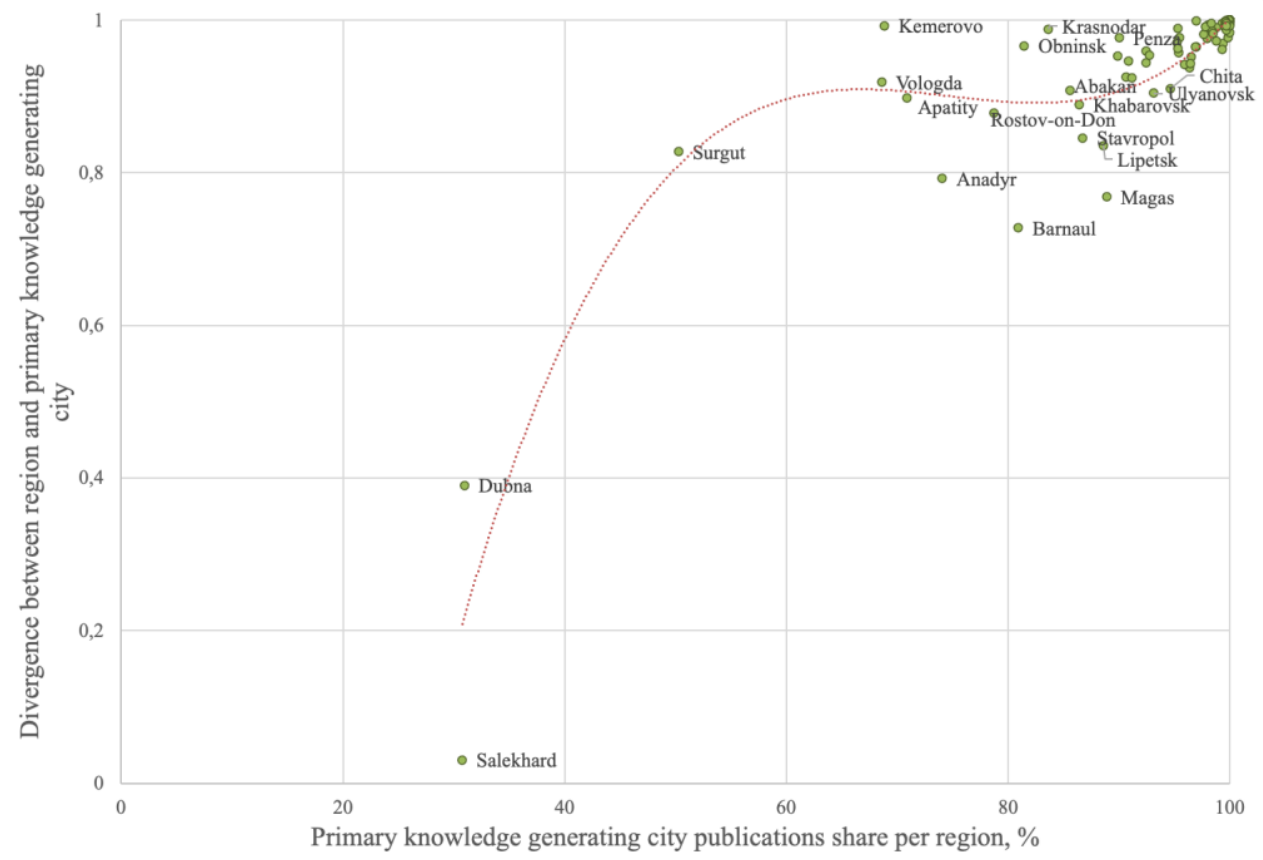

Figure 3: Interdependence of scientometric profiles between primary knowledge-generating cities and regions by input to knowledge production system, 2013-17 
The relationship between the studied characteristics is established by calculating the correlation coefficient (1), the value of which is 0.9371 . This indicates a direct dependence between the studied characteristics, and the strength of the relationship on the Chaddock's scale is very high. In other words, the difference between scientometric portrait of the region is highly dependent on the contribution of its primary KGC to the total volume of research affiliated with the region.

The coefficient of determination (denoted by R2) calculated by the formula ( 2 ) is equal to 0.8782 . This means that factor $X$ determines $87.82 \%$ of the variance of the dependent variable $Y$. In other words, the share of publications of the primary KGC in the total volume of publications in the region is a determining factor for the degree of difference between the scientometric portrait of the region and its KGCS.

The average approximation error characterizing the adequacy of the regression model is calculated by formula (3) and amounts to $10.1249 \%$. Since the value of the average approximation error is less than $15 \%$, this indicates a well-chosen model of the equation. The significance of the regression model is tested using Fisher's F-test. Since the actual value (185.0027) of the F-test criterion turned out to be more than the tabular (2.7233), the constructed model is proven significant.

Next, we modelled scientometric portraits of 4 Russian KGCs in the mirror of KIOs concentrated within urban boundaries, with the total number of Scopus publications for 2013-17 above the threshold value. Table 1 illustrates the scientometric characteristics of organizations in relation to the aggregate values of the city's indicators, highlighting the primary and secondary organizations.

Table 1: Scientometric analysis of knowledge-intensive organisations in Kaliningrad, Khabarovsk, Perm, Nalchik

\begin{tabular}{|c|c|c|c|c|c|c|c|c|}
\hline \multirow{2}{*}{ Institution } & Authors & $\begin{array}{l}\text { Scholarly } \\
\text { Output }\end{array}$ & Citations & \multirow{2}{*}{$\sum_{4}^{\bar{u}}$} & \multirow{2}{*}{ 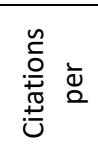 } & \multirow{2}{*}{ 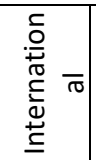 } & \multirow{2}{*}{ 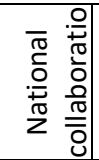 } & \multirow{2}{*}{ 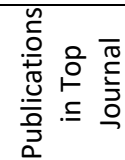 } \\
\hline & \multicolumn{3}{|c|}{$\begin{array}{c}\text { for the city in units. } \\
\text { for organizations in \% of the city }\end{array}$} & & & & & \\
\hline 1. City Perm & 5734 & 4017 & 14463 & 0.4 & 3.6 & 12.3 & 40.9 & 2.7 \\
\hline \multicolumn{9}{|c|}{ Including knowledge-intensive organisations: } \\
\hline $\begin{array}{l}\text { Perm National Research Polytechnic } \\
\text { University }\end{array}$ & 36.6 & 41.8 & 35.2 & 0.5 & 3.0 & 8.4 & 34.7 & 1.8 \\
\hline $\begin{array}{l}\text { Perm State National Research } \\
\text { University }\end{array}$ & 28.3 & 27.2 & 29.8 & 0.4 & 4.0 & 17.2 & 46.2 & 5.6 \\
\hline $\begin{array}{l}\text { Institute of Continuous Media } \\
\text { Mechanics of the Ural Branch of } \\
\text { Russian Academy of Science }\end{array}$ & 11.3 & 16.2 & 26.2 & 0.6 & 5.8 & 23.8 & 56.7 & 8.4 \\
\hline Perm State Medical University & 15.7 & 7.2 & 4.5 & 0.2 & 2.2 & 6.5 & 59.8 & 1.0 \\
\hline $\begin{array}{l}\text { Institute of Technical Chemistry of Ural } \\
\text { Branch of the RAS }\end{array}$ & 5.0 & 5.5 & 6.3 & 0.3 & 4.1 & 7.7 & 87.4 & 3.6 \\
\hline $\begin{array}{l}\text { Institute of Ecology and Genetics of } \\
\text { Microorganisms Ural Branch of the } \\
\text { Russian Academy of Sciences }\end{array}$ & 5.3 & 5.3 & 8.5 & 0.5 & 5.8 & 6.2 & 89.1 & 4.3 \\
\hline Perm State Pharmaceutical Academy & 4.3 & 4.1 & 3.7 & 0.2 & 3.3 & 6.1 & 63.8 & 0.0 \\
\hline RAS - Mining Institute, Ural Branch & 5.7 & 3.6 & 2.8 & 0.4 & 2.8 & 11.9 & 48.3 & 3.5 \\
\hline $\begin{array}{l}\text { Perm State Humanitarian Pedagogical } \\
\text { University }\end{array}$ & 3.2 & 3.5 & 2.7 & 0.3 & 2.8 & 5.0 & 44.0 & 1.4 \\
\hline $\begin{array}{l}\text { Federal Scientific Center for Medical } \\
\text { and Preventive Health Risk } \\
\text { Management Technologies }\end{array}$ & 2.4 & 1.9 & 1.7 & 0.3 & 3.2 & 1.3 & 71.1 & 1.3 \\
\hline Lukoil & 1.6 & 1.5 & 0.8 & 0.3 & 1.9 & 0.0 & 56.5 & 0.0 \\
\hline $\begin{array}{l}\text { RAS - Perm Federal Research Center, } \\
\text { Ural Branch }\end{array}$ & 0.6 & 0.9 & 0.8 & 0.4 & 3.3 & 0.0 & 82.9 & 0.0 \\
\hline 2. City Khabarovsk & 2330 & 1208 & 7640 & 0.6 & 6.3 & 15.9 & 53.9 & 5.6 \\
\hline \multicolumn{9}{|c|}{ Including knowledge-intensive organisations: } \\
\hline Pacific National University & 20.9 & 24.8 & 10.7 & 0.4 & 2.7 & 11,7 & 59.9 & 1.0 \\
\hline Far Eastern State Transport University & 22.0 & 23.7 & 51.2 & 1.3 & 13.7 & 26,9 & 45.8 & 14.0 \\
\hline Institute of Tectonics and Geophysics & 10.8 & 11.6 & 12.0 & 0.5 & 6.6 & 18,6 & 64.3 & 7.1 \\
\hline Institute of Mining FEB RAS & 9.0 & 9.3 & 5.3 & 0.3 & 3.6 & 0,9 & 75.0 & 0.9 \\
\hline Computing Center FEB RAS & 5.1 & 8.9 & 5.4 & 0.6 & 3.8 & 6,5 & 59.8 & 1.9 \\
\hline
\end{tabular}




\begin{tabular}{|c|c|c|c|c|c|c|c|c|}
\hline \multirow{2}{*}{ Institution } & Authors & $\begin{array}{c}\text { Scholarly } \\
\text { Output }\end{array}$ & Citations & \multirow{2}{*}{$\sum_{4}^{\bar{u}}$} & \multirow{2}{*}{ 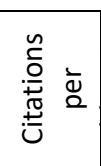 } & \multirow{2}{*}{ 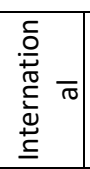 } & \multirow{2}{*}{ 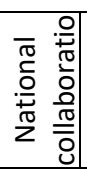 } & \multirow{2}{*}{ 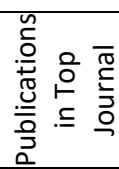 } \\
\hline & \multicolumn{3}{|c|}{$\begin{array}{c}\text { for the city in units. } \\
\text { for organizations in \% of the city }\end{array}$} & & & & & \\
\hline $\begin{array}{l}\text { Institute of Water and Ecology } \\
\text { Problems of the Far Eastern Branch of } \\
\text { the Russian Academy of Sciences }\end{array}$ & 11.2 & 8.7 & 10.5 & 0.5 & 7.6 & 18,1 & 64.8 & 3.8 \\
\hline $\begin{array}{l}\text { Institute for Material Studies, } \\
\text { Khabarovsk Scientific Center, FEB RAS }\end{array}$ & 4.1 & 7.1 & 3.7 & 0.3 & 3.3 & 2,3 & 81.4 & 2.3 \\
\hline $\begin{array}{l}\text { Far Eastern Scientific Center of } \\
\text { Physiology and Pathology of Breath SB } \\
\text { RAMS }\end{array}$ & 2.4 & 6.5 & 6.6 & 0.4 & 6,5 & 34,6 & 44,9 & 2,6 \\
\hline Far Eastern State Medical University & 11.3 & 5.6 & 3.1 & 0.2 & 3,4 & 23,5 & 50,0 & 5,9 \\
\hline $\begin{array}{l}\text { Far Eastern State Academy of Physical } \\
\text { Culture }\end{array}$ & 1.2 & 1.7 & 0.1 & 0.1 & 0,4 & 0,0 & 33,3 & 0,0 \\
\hline $\begin{array}{l}\text { Khabarovsk State Academy of } \\
\text { Economics and Law }\end{array}$ & 1.5 & 1.7 & 0.5 & 0.7 & 2,0 & 30,0 & 45,0 & 0,0 \\
\hline 3. City Kaliningrad & 3334 & 1217 & 8636 & 0.7 & 7.1 & 36.2 & 38.1 & 9.1 \\
\hline \multicolumn{9}{|c|}{ Including knowledge-intensive organisations: } \\
\hline $\begin{array}{l}\text { Immanuel Kant Baltic Federal } \\
\text { University }\end{array}$ & 66.9 & 68.9 & 65.7 & 0.7 & 6.8 & 36.6 & 41.7 & 9.5 \\
\hline $\begin{array}{l}\text { Atlantic Branch, Shirshov Institute of } \\
\text { Oceanology }\end{array}$ & 10.0 & 12.1 & 13.4 & 0.8 & 7.9 & 31.3 & 55.8 & 9.5 \\
\hline Kaliningrad State Technical University & 1.4 & 12.6 & 6.2 & 0.4 & 3.5 & 21.6 & 32.0 & 0.0 \\
\hline AtlantNIRO & 2.8 & 1.4 & 2.2 & 0.7 & 11.1 & 23.5 & 23.5 & 0.0 \\
\hline 4. City Nalchik & 1110 & 712 & 1886 & 0.35 & 2.6 & 7.4 & 45.5 & 1.7 \\
\hline \multicolumn{9}{|c|}{ Including knowledge-intensive organisations: } \\
\hline Kabardino-Balkarian State University & 72.0 & 74.4 & 69.9 & 0.4 & 2.5 & 6.6 & 50.9 & 0.6 \\
\hline $\begin{array}{l}\text { Institute of Applied Mathematics and } \\
\text { Automation KBSC RAS }\end{array}$ & 4.2 & 9.4 & 16.0 & 0.6 & 4.5 & 6.0 & 6.0 & 4.5 \\
\hline $\begin{array}{l}\text { Kabardino-Balkarian State Agricultural } \\
\text { University }\end{array}$ & 10.2 & 6.9 & 4.2 & 0.3 & 1.6 & 4.1 & 87.8 & 0.0 \\
\hline $\begin{array}{l}\text { Tembotov Institute of Ecology of } \\
\text { Mountain Territories RAS }\end{array}$ & 6.0 & 4.5 & 3.2 & 0.2 & 1.9 & 9.4 & 62.5 & 3.1 \\
\hline $\begin{array}{l}\text { Institute for Computer Science and } \\
\text { Problems of Regional Management } \\
\text { KBSC RAS }\end{array}$ & 6.7 & 3.2 & 5.8 & 0.4 & 4.8 & 26.1 & 21.7 & 13.0 \\
\hline
\end{tabular}

Source: calculated by the authors based on data from the Scopus database

The cities with a higher diversity of KOIs (12 and 11) - Perm and Khabarovsk, do not have a pronounced leader among organizations in terms of the scholarly output. The share of the leading Perm National Research Polytechnic University among Perm KOIs is $41.8 \%$, and the Pacific National University in Khabarovsk is $24.8 \%$. In Kaliningrad and Nalchik, the picture is different: there is a small number of KIOs and against their background a strong leader in the volume of publications stands out - Immanuel Kant Baltic Federal University in Kaliningrad and Kabardino-Balkarian State University in Nalchik. In order to better see the differences between the cities under study in the formation of their scientometric portraits, we assessed the distribution of KIOs in relation to their share in terms of the volume of research output in the city-wide volume and the degree of similarity with the city in terms of the array of scientometric indicators (Fig. 4). 

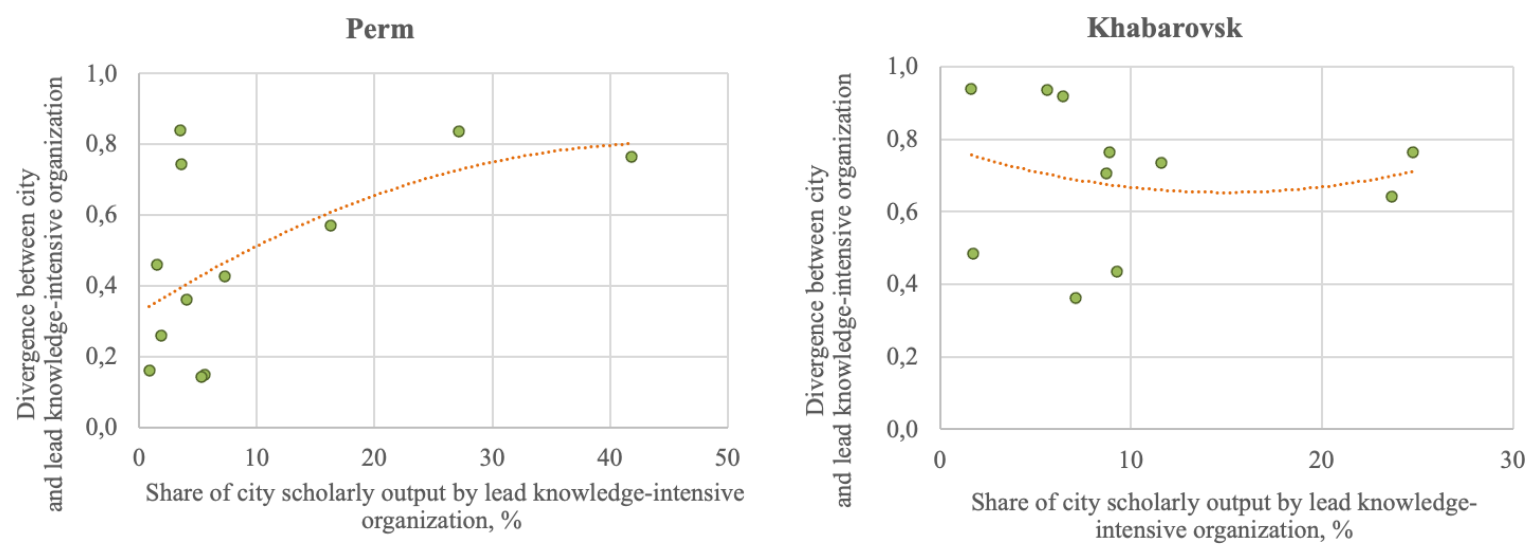

Nalchik

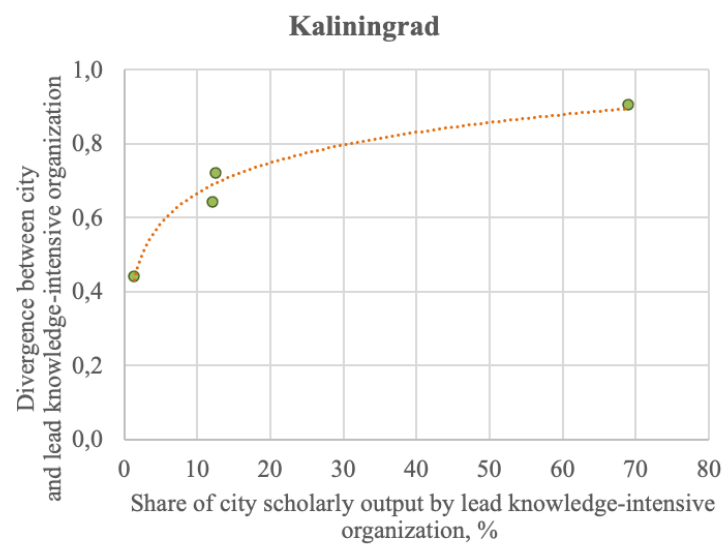

Figure 4: Interdependence of scientometric profiles between primary knowledge-generating cities and knowledge-intensive organisations by research output, 2013-17

The correlation coefficient between the "divergence of KGC and KIO" and the "share of KGC research output by lead $\mathrm{KIO}^{\circ}$ is 0.717 , and between the "divergence of KGC and lead KIO" and the "share of KGC research output by lead $\mathrm{KIO}^{\prime \prime}$ is 0.734 . This indicates a strong relationship between these indicators. We have identified an interesting pattern: if there is one leading KIO (examples of Nalchik and Kaliningrad), then it almost completely determines the knowledge profile of the city. In this case, the divergence between city and lead knowledgeintensive organization is over 0.8 . However, when the knowledge production capacity of the city is scattered across numerous organizations without strong polarization (examples of Perm and Khabarovsk), the KIO with the greatest contribution to the volume of research output of the city ceases to have such a tangible impact on its scientometric portrait. The average scientometric indicators of the city tend to repeat the features of the least productive organizations, each occupying less than $10 \%$ of the total volume of publications.

\section{Discussion}

This study examines the poly-scale structure of the regional knowledge production system. We have analysed a dataset for 83 regions of Russia through the prism of 440 scientometric portraits of their cities - KnowledgeGenerating Cities (KGCs). Additionally, 4 cases of Russian cities located in different geographic regions and having a different structure of the regional knowledge production system were studied to assess the intracity heterogeneity in the generation of scientific knowledge. Data suggests that Russia has significant gaps between regions and within them by knowledge production indicators, which is ideal for studying inequality of the knowledge landscape in its diversity. In Russia, there are regions where there is only one KGC, and regions with a high concentration of KGCs - more than 10, and even up to 56 in Moscow agglomeration. Similar gaps are typical for the inner-city knowledge production space of Russian cities, which have a different number of knowledge-intensive organizations (KIOs): the gap is more than double in the studied examples.

Given such a variety of setups in regional knowledge production systems, there cannot be implemented a unified "one-size-fits-all" approach, method, or tools to knowledge management. A place-sensitive territorial development policy should be in place (Heimeriks et al., 2019). Meanwhile, the aggregated regional data is heavily used for administrative purposes at the federal, regional, and city levels. Our study shows that in order 
to increase the effectiveness of knowledge management in terms of creating a more adequate information base for decision-making by regions, it is necessary, firstly, to evaluate the model of the regional knowledge production system formed. If it has a distributed, scattered character, then the level of the region is uninformative, and it is necessary to evaluate individual KGCs for effective knowledge management. If the model of the knowledge production system of the region is described by a pronounced centre-peripheral pattern, then the scientometric dynamics of the region and its primary KGC will repeat each other. In this case, the city level assessment will unveil numerous small secondary KGCs that are invisible beyond the scale of the primary KGC but, as previously defined by Isaksen and Trippl (2017), these cities form a 'mosaic of regional innovation patterns'.

Secondly, moving down to the level of the city, one should understand what knowledge-intensive organizations form its knowledge production system. We have identified two main urban models: polarized - when there is a lead $\mathrm{KIO}$ that provides over $80 \%$ of all publications of the city; distributed - when there are several KIOs holding similar positions in terms of contribution to the total volume of research output of the city. In the first case, the dynamics of the city's knowledge production is set by its main research centre. In the second case, a detailed analysis of the existing KIOs is required, since the average level of scientometric indicators of a city often translates the image not of its leading organization, but of those lagging behind.

The results obtained verify the research hypothesis put forward. The knowledge portrait of the region almost completely reflects the portrait of its primary KGC in the case when there is a significant gap between the primary and secondary KGCs by the scientometric indicators considered. Moreover, the pattern is true for regions with different numbers of KGCs, both mono- and poly-centric. Thus, when scientometric analysis applied for studying regional knowledge production (research) capabilities, the two options are possible. a) Evaluation done through the prism of region's primary KGC obscures secondary KGCs in the case of a strong centre-peripheral model of knowledge production. b) Given the case of a distributed regional knowledge production system with several KGCs of similar size, the regional scientometric portrait is distorted and the results obtained do not reflect the knowledge generation dynamics in any of its cities - KGCs. In our opinion, the regional scale assessment generates a false idea of the region's knowledge production system in cases when a single KGC does not generate $80-90 \%$ of the total research output. This could explain the identified 'stubborn path-dependencies' by Klochikhin (2012) and partially determine the 'cold spots' defined by Bornmann and de Moya Angeon (2019).

A similar situation is observed when we try to model a knowledge portrait of a city, which is also an aggregated representation of reality. The high polarization of the urban knowledge production domain makes it possible to build direct links between the indicators of the city and its most productive organization. At the same time, not one, but several KIOs may be located in a city, most of which will be small in research output. In the case when the knowledge space is developed more evenly and has a higher organizational density, the distortions of the aggregated indicators of the city are rather high and do not reflect the real picture, which requires lowering the analysis to the organizational level. This was relevant, for example, in relation to Khabarovsk.

\section{Conclusion}

Unrepresentative data is a significant obstacle to the implementation of effective knowledge management policies. This could partially explain the overwhelming path-dependencies of regional innovation trajectories registered in the knowledge landscape as the aggregate regional level data is highly resistant to local change, blurring the recent initiatives and trends behind the long-lasting mainstream (Cooper 2006; Crescenzi and Jaax, 2017; Klochikhin 2013). In such cases, the city level is more informative, since there is less distortion when aggregating scientometric data representing the knowledge production domain of the innovation system.

The research results are consistent with the findings that emphasize the importance of studying the geography of knowledge at the city level (Ivaldi et al., 2020; Lever, 2002; Penco et al., 2020). Moreover, we support the conclusions made by Chica and Marmolejo (2016) that determined the tendency of knowledge-based industries to be spatially concentrated in the large metropolitan cores along with universities and innovation complexes. As well as Pancholi et al. (2019), who argue for an even higher density of innovation and knowledge-intensive activities within the knowledge and innovation spaces. Given the inequality and divergence being verified by most studies across the globe, supporting the everlasting concept of core-periphery, a similar poly-scale approach has to be applied at intra-urban level - between city districts. For instance, a study of Zandiatashbar 
and Hamidi (2018) suggest that knowledge intensive business services are more likely to locate in the largest cities, clustered in central business districts.

Our study shows that the asymmetry of information on knowledge capital increases if data is limited to one hierarchical level - organisation, city or region. Single scale datasets negatively affect the decision-making, thus, influencing the quality of knowledge management. Developing knowledge policies based on an aggregated outlook of the knowledge landscape is like manoeuvring a ship between icebergs without a clear picture of their actual size, quantity, or location. Shortage or inaccuracy of information increases the probability of collision with an iceberg, i.e. managerial failure. Moreover, the 'helicopter view' provides poor prospects of smaller locations driving into false conclusions of these places being insignificant and of "no future" (Rodríguez-Pose, 2018). The results of our study suggest that the multiscale approach allows reducing information uncertainty, on the one hand, demonstrating inter-regional dynamics, and on the other, intra-regional specifics. This unveils the territorial knowledge system more holistically, and therefore see and forecast its growth nodes or identify bottlenecks that hinder the exponential growth of the knowledge-based economy.

Further studies could benefit from widening the region-city-organization sample and expanding on to other countries. The identified pattern of multilevel overlaps could be further verified using other sources of data, such as patents. Moreover, the qualitative dimension could be further analyzed, considering the specialization and other parameters.

\section{Acknowledgements}

The reported study was funded by RSF according to the research project No. 19-77-00053 «Knowledge geography: clustering and networking of national competence centers».

\section{References}

Asheim, B. T., Isaksen, A., \& Trippl, M. (2019). Advanced introduction to regional innovation systems. Elgar advanced introductions. Edward Elgar Publishing.

Bathelty, H. \& Cohendet, P. (2014). The creation of knowledge: Local building, global accessing and economic development-toward an agenda. Journal of Economic Geography, 14(5), 1-14. https://doi.org/10.1093/jeg/lbu027

Berger, A., \& Brem, A. (2016). Innovation Hub How-To: Lessons from Silicon Valley. Global Business and Organizational Excellence, 35(5), 58-70. https://doi.org/10.1002/joe.21698

Bornmann, L., \& de Moya Angeon, F. (2019). Hot and cold spots in the US research: A spatial analysis of bibliometric data on the institutional level. Journal of Information Science, 45(1), 84-91 https://doi.org/10.1177/0165551518782829

Breschi, S., \& Lenzi, C. (2016). Co-invention networks and inventive productivity in US cities. Journal of Urban Economics, 92, 66-75. https://doi.org/10.1016/j.jue.2015.12.003

Camagni, R. (2017). Territorial capital, competitiveness and regional development. In: Huggins R., Piers T. (Eds.). Handbook of regions and competitiveness. Edward Elgar Publishing. https://doi.org/10.4337/9781783475018.00016

Capello, R., \& Lenzi, C. (2018). Regional innovation patterns from an evolutionary perspective. Regional Studies, 52(2), 159-171. https://doi.org/10.1080/00343404.2017.1296943

Carayannis, E. G., Grigoroudis, E., Campbell, D. F., Meissner, D., \& Stamati, D. (2018). The ecosystem as helix: an exploratory theory-building study of regional co-opetitive entrepreneurial ecosystems as Quadruple/Quintuple Helix Innovation Models. R\&D Management, 48(1), 148-162. https://doi.org/10.1111/radm.12300

Carrillo, J., Yigitcanlar, T., Garcia, B., \& Lönnqvist, A. (2014). Knowledge and the city: Concepts, applications and trends of knowledge-based urban development. Routledge, New York.

Chica, J.E., \& Marmolejo, C. (2016). Knowledge economy and metropolitan growth: Barcelona and Helsinki metropolitan areas as case studies. International Journal of Knowledge-Based Development, 7(1), 22-42. https://doi.org/10.1504/IJKBD.2016.075436Pancholi et al. (2019)

Clarke, G., Martin, R., \& Tyler, P. (2016). Divergent cities? unequal urban growth and development. Cambridge Journal of Regions, Economy and Society, 9(2), 259-268. https://doi.org/10.1093/cjres/rsw011

Cooper, J. (2006). Of BRICs and brains: Comparing Russia with China, India, and other populous emerging economies. Eurasian Geography and Economics, 47(3), 255-84. https://doi.org/10.2747/15387216.47.3.255 
Crescenzi, R., \& Jaax, A. (2017). Innovation in Russia: The territorial dimension. Economic Geography, 93(1), 6688. https://doi.org/10.1080/00130095.2016.1208532

Csomós, G. (2018). A spatial scientometric analysis of the publication output of cities worldwide. Journal of Informetrics, 12(2), 547-566. https://doi.org/10.1016/j.joi.2018.05.003

Czarny, R.M. (2017). The Phenomenon of the Öresund Region. In: A Modern Nordic Saga: Politics, Economy and Society. Springer, Cham. https://doi.org/10.1007/978-3-319-42363-0_3

Davids, M., \& Frenken, K. (2018). Proximity, knowledge base and the innovation process: Towards an integrated framework. Regional Studies, 52(1), 23-34. https://doi.org/10.1080/00343404.2017.1287349

Dziallas, M., \& Blind, K. (2019). Innovation indicators throughout the innovation process: An extensive literature analysis. Technovation, 80, 3-29. https://doi.org/10.1016/j.technovation.2018.05.005

Edvardsson, I.R., Yigitcanlar, T., \& Pancholi, S. (2016). Knowledge city research and practice under the microscope: A review of empirical findings. Knowledge Management Research and Practice, 14(4), 537564. https://doi.org/10.1057/s41275-016-0003-0

Esmaeilpoorarabi, N., Yigitcanlar, T., \& Guaralda, M. (2016). Place quality and urban competitiveness symbiosis? A position paper. International Journal of Knowledge-Based Development, 7(1), 4-21. https://doi.org/10.1504/IJKBD.2016.075444

Fernandes, C., Farinha, L., Ferreira, J. J., Asheim, B., \& Rutten, R. (2020). Regional innovation systems: what can we learn from 25 years of scientific achievements? Regional Studies, 55(3), 373-376. https://doi.org/10.1080/00343404.2020.1782878

Freeman, C., \& Soete, L. (2009). Developing science, technology and innovation indicators: What we can learn from the past. Research policy, 38(4), 583-589. https://doi.org/10.1016/j.respol.2009.01.018

Frenken, K, Hardeman, S, \& Hoekman, J. (2009). Spatial scientometrics: towards a cumulative research program. Journal of Informetrics, 3(3), 222-232. https://doi.org/10.1016/j.joi.2009.03.005

Heimeriks, G., \& Boschma, R. (2014). The path- and place-dependent nature of scientific knowledge production in biotech 1986-2008. Journal of Economic Growth, 14 (2), 339-364. https://doi.org/10.1093/jeg/lbs052

Heimeriks, G., Li, D., Lamers, W., Meijer, I., \& Yegros, A. (2019). Scientific knowledge production in European regions: Patterns of growth, diversity and complexity. European Planning Studies, 27(11), 2123-2143. doi:10.1080/09654313.2019.1645814

Isaksen, A., \& Trippl, M. (2017). Innovation in space: the mosaic of regional innovation patterns. Oxford Review of Economic Policy, 33(1), 122-140. https://doi.org/10.1093/oxrep/grw035

Ivaldi, E., Penco, L., Isola, G., \& Musso, E. (2020). Smart sustainable cities and the urban knowledge-based economy: A NUTS3 level analysis. Social Indicators Research, 150, 45-72. https://doi.org/10.1007/s11205020-02292-0

Järvi, K., Almpanopoulou, A., \& Ritala, P. (2018). Organization of knowledge ecosystems: Prefigurative and partial forms. Research Policy, 47(8), 1523-1537. https://doi.org/10.1016/j.techfore.2020.119987

Klochikhin, E.A. (2012). Russia's innovation policy: Stubborn path-dependencies and new approaches. Research Policy, 41(9), 1620-1630. https://doi.org/10.1016/j.respol.2012.03.023

Kogler, D. F., Heimeriks, G., \& Leydesdorff, L. (2018). Patent portfolio analysis of cities: statistics and maps of technological inventiveness. European Planning Studies, 26(11), 2256-2278. doi:10.1080/09654313.2018.1530147

Kogler, D., \& Whittle, A. (2018). The Geography of Knowledge Creation: Technological Relatedness and Regional Smart Specialisation Strategies. In A. Paasi, J. Harrison, \& M. Jones (Eds.), Handbook on the Geographies of Regions and Territories (pp. 153-168). London: Edward Elgar.

Lever, W.F. (2002). Correlating the knowledge-base of cities with economic growth. Urban Studies, 39(5-6), 859870. https://doi.org/10.1080/00420980220128345

Leydesdorff, L. (2012). The triple helix, quadruple helix, ..., and an N-tuple of helices: Explanatory models for analyzing the knowledge-based economy? Journal of the Knowledge Economy, 3(1), 25-35. https://doi.org/10.1007/s13132-011-0049-4

Liu, W., Tan, R., Li, Z., Cao, G., \& Yu, F. (2020). A patent-based method for monitoring the development of technological innovations based on knowledge diffusion. Journal of Knowledge Management, 25(2), 380401. doi:10.1108/JKM-09-2019-0502

Makkonen, T., \& Weidenfeld, A. (2016). Knowledge-based urban development of cross-border twin cities. International Journal of Knowledge-Based Development, 7(4), 389-406. doi:10.1504/IJKBD.2016.080881

Metaxiotis, K., \& Ergazakis, K. (2008). Exploring stakeholder knowledge partnerships in a knowledge city: a conceptual model. Journal of Knowledge Management, 12(5), 137-150. https://doi.org/10.1108/13673270810902993 
Mikhaylov, A.S. (2018). Socio-spatial dynamics, networks and modelling of regional milieu. Entrepreneurship and Sustainability Issues, 5(4), 1020-1030. http://doi.org/10.9770/jesi.2018.5.4(22)

Mikhaylova, A.A., \& Mikhaylov, A.S. (2016). Re-distribution of knowledge for innovation around Russia. International Journal of Technological Learning, Innovation and Development, 8(1), 37-56. https://doi.org/10.1504/IJTLID.2016.075179

Mohnen P. (2019). R\&D, Innovation and Productivity. In: ten Raa T., Greene W. (eds) The Palgrave Handbook of Economic Performance Analysis. Palgrave Macmillan, Cham. https://doi.org/10.1007/978-3-030-237271_4

Park, S.C. (2014). Innovation policy and strategic value for building a cross-border cluster in Denmark and Sweden. Al \& society, 29(3), 363-375. 10.1007/s00146-013-0460-4

Penco, L., Ivaldi, E., Bruzzi, C., \& Musso, E. (2020). Knowledge-based urban environments and entrepreneurship: Inside EU cities. Cities, 96. https://doi.org/10.1016/j.cities.2019.102443

Perret, J. K. (2019). Re-evaluating the knowledge production function for the regions of the Russian Federation. Journal of the Knowledge Economy, 10(2), 670-694. https://doi.org/10.1007/s13132-017-0475-z

Prokop V., \& Stejskal J. (2018). The Effects of Cooperation and Knowledge Spillovers in Knowledge Environment. In: Stejskal, J., Hajek, P., \& Hudec, O. (Eds.). Knowledge spillovers in regional innovation systems. Berlin: Springer, 3-46. https://doi.org/10.1007/978-3-319-67029-4_1

Rodríguez-Pose, A. (2018). The revenge of the places that don't matter (and what to do about it). Cambridge Journal of Regions, Economy and Society, 11(1), 189-209. https://doi.org/10.1093/cjres/rsx024

Sánchez-Moral, S., Bontje, M., \& Musterd, S. (2018). Understanding knowledge and creativity-based development in well-established cities and urban regions. International Journal of Knowledge-Based Development, 9(4), 361-385. https://www.doi.org/10.1504/IJKBD.2018.096425

Sawant, H., \& Jain, K. K. (2017). Issues related to knowledge in knowledge intensive organisations - a literature review. International Journal of Knowledge Management Studies, 8(3-4), 299-315. https://doi.org/10.1504/IJKMS.2017.087072

Scaringella, L., \& Radziwon, A. (2018). Innovation, entrepreneurial, knowledge, and business ecosystems: Old wine in new bottles? Technological Forecasting and Social Change, 136, 59-87. https://doi.org/10.1016/j.techfore.2017.09.023

Shearmur, R. (2017). Urban bias in innovation studies. In: Bathelt H., Cohendet P., Henn S., \& Simon L. (Eds.). The Elgar companion to innovation and knowledge creation. Edward Elgar Publishing. https://doi.org/10.4337/9781782548522.00037

Solesvik, M.Z. (2017). The triple helix model for regional development and innovation: context of Nordic countries. Forum Scientiae Oeconomia, 5(4), 5-21. https://doi.org/10.23762/FSO_VOL5NO4_17_1

Stejskal, J., \& Hajek, P. (2016). Measuring the effectiveness of cooperative ties in knowledge networks. Paper presented at the Proceedings of the European Conference on Knowledge Management, ECKM, 2016January 831-839.

Stek, P.E. (2020). Mapping high R\&D city-regions worldwide: A patent heat map approach. Quality and Quantity, 54(1), 279-296. https://doi.org/10.1007/s11135-019-00874-w

Szulanski, G. (2002). Sticky knowledge: Barriers to knowing in the firm. SAGE Publications Ltd, https://www.doi.org/10.4135/9781446218761

Taques, F.H., López, M.G., Basso, L.F., \& Areal, N. (2021). Indicators used to measure service innovation and manufacturing innovation. Journal of Innovation \& Knowledge, $6 \quad$ (1), 11-26. https://doi.org/10.1016/j.jik.2019.12.001

Tödtling, F., \& Trippl, M. (2018). Regional innovation policies for new path development-beyond neo-liberal and traditional systemic views. European Planning Studies, 26(9), 1779-1795. https://doi.org/10.1080/09654313.2018.1457140

Uyarra, E., Flanagan, K., Magro, E., Wilson, J. R., \& Sotarauta, M. (2017). Understanding regional innovation policy dynamics: Actors, agency and learning. Environment and Planning C: Politics and Space, 35(4), 559568. https://doi.org/10.1177/2399654417705914

Yigitcanlar, T. (2009). Planning for knowledge-based development: Global perspectives. Journal of Knowledge Management, 13(5), 228-242. https://doi.org/10.1108/13673270910988079

Yigitcanlar, T. (2014). Position paper: Benchmarking the performance of global and emerging knowledge cities. Expert Systems with Applications, 41(12), 5549-5559. https://doi.org/10.1016/j.eswa.2014.03.032

Yigitcanlar, T., \& Bulu, M. (2016). Urban Knowledge and Innovation Spaces. Journal of Urban Technology, 23(1), 1-9, https://doi.org/10.1080/10630732.2016.1164443 
Yigitcanlar, T., \& Lönnqvist, A. (2013). Benchmarking knowledge-based urban development performance: Results from the international comparison of HELSINKI. Cities, 31(1), 357-369. https://doi.org/10.1016/j.cities.2012.11.005

Zandiatashbar, A., \& Hamidi, S. (2018). Impacts of transit and walking amenities on robust local knowledge economy. Cities, 81, 161-171. https://doi.org/10.1016/j.cities.2018.04.005 